\title{
Diffusion of Refractory Elements in Ni-X-Y (X, Y: Re, W, Ru, Al) Ternary Alloys
}

\author{
Masataka Hattori ${ }^{1, * 1}$, Nobuhiro Goto ${ }^{2, * 2}$, Yoshinori Murata ${ }^{1}$, \\ Toshiyuki Koyama ${ }^{3}$ and Masahiko Morinaga ${ }^{1}$ \\ ${ }^{1}$ Department of Materials, Physics and Energy Engineering, Graduate School of Engineering, Nagoya University, \\ Nagoya 464-8603, Japan \\ ${ }^{2}$ School of Engineering, Nagoya University, Nagoya 464-8603, Japan \\ ${ }^{3}$ National Institute for Materials Science, Tsukuba 305-0047, Japan
}

Interdiffusion coefficients of the refractory elements in $\mathrm{Ni}-\mathrm{X}-\mathrm{Y}(\mathrm{X}, \mathrm{Y}=\mathrm{W}, \mathrm{Re}, \mathrm{Ru}, \mathrm{Al})$ ternary systems, which are the fundamental systems of Ni-based superalloys, were estimated by a series of experiments using diffusion couples. The modified ternary Boltzmann-Matano method was employed for analyzing the experimental data. The cross interdiffusion coefficients were smaller than the main interdiffusion coefficients in all systems. Especially, the cross interdiffusion coefficient $\tilde{D}_{\mathrm{Re}}^{\mathrm{Ni}}$ is much smaller by an order of magnitude than the main interdiffusion coefficient $\tilde{D}_{\mathrm{ReRe}}^{\mathrm{Ni}}$ in Ni-Ru-Re system. This result indicates that the thermodynamical interaction parameter (Wagner's interaction parameter) between $\mathrm{Ru}$ and Re is negligible, and implies that Ru does not affect the distribution behaviour of Re into $\gamma$ and $\gamma^{\prime}$ phases.

(Received September 26, 2005; Accepted December 7, 2005; Published February 15, 2006)

Keywords: interdiffusion coefficient, nickel-based superalloy, refractory element, rhenium, tungsten, ruthenium

\section{Introduction}

In order to increase the strength of Ni-based superalloys at elevated temperatures, refractory elements such as W and Re are added to them. ${ }^{1,2)}$ But an excess amount of refractory elements leads to the formation of the brittle TCP (topologically close-packed) phases, ${ }^{3)}$ resulting in shortening of the creep rupture life. On the other hand, it is well known that $\mathrm{Ru}$ suppresses the formation of the TCP phases phenomenologically, but the mechanism is still not clear. ${ }^{4)}$

Diffusion coefficients in multi-component alloys are known to correlate with the thermodynamic interaction parameters of the component atoms. ${ }^{5)}$ Thus it is important to examine the diffusion of alloying elements in superalloys ${ }^{6)}$ in order to make it clear the behaviour of these elements in the alloys. But there is no available data on diffusion of multicomponent systems containing $\mathrm{Ru}$ at the present moment, even in $\mathrm{Ni}-\mathrm{Al}-\mathrm{X}(\mathrm{X}: \mathrm{Re}, \mathrm{W}, \mathrm{Ru})$ ternary systems, which are the most important fundamental systems of Ni-based superalloys. As mentioned above, the alloying behaviour of Ru in nickel-based superalloys has open to debate. Thus the examination of the diffusion coefficients of $\mathrm{Ru}, \mathrm{Re}$ and $\mathrm{W}$ in $\mathrm{Ni}-\mathrm{Ru}-\mathrm{X}(\mathrm{X}$ : Re, W) ternary system is also important in order to discuss the thermodynamical interaction between $\mathrm{Ru}$ and the refractory elements in $\mathrm{Ni}$ alloys.

The purpose of this study is to measure the diffusion coefficients of $\mathrm{Ru}, \mathrm{Re}$ and $\mathrm{W}$ in $\mathrm{Ni}-\mathrm{X}-\mathrm{Y}(\mathrm{X}, \mathrm{Y}$ : Re, W, Ru, $\mathrm{Al}$ ) ternary systems, which are the fundamental systems of Ni-based superalloys.

\section{Theory}

In this study, the modified ternary Boltzmann-Matano

\footnotetext{
${ }^{* 1}$ Graduate Student, Nagoya University; Present address: Mitsubishi Heavy Industries, LTD., Takasago.

${ }^{* 2}$ Undergraduate Student, Nagoya University
}

method was adopted to estimate the interdiffusion coefficients. This method enables to calculate the interdiffusion coefficients without determination of the Matano plane, and hence the diffusion coefficients of multi-component alloys can be estimated with accuracy. ${ }^{7)}$ According to Whittle et al., ${ }^{8)}$ interdiffusion coefficients relate to the experimental values obtained from the concentration profiles as the following equations.

$$
\begin{aligned}
\tilde{D}_{i i}^{k} & +\left(d C_{j} / d C_{i}\right) \tilde{D}_{i j}^{k}=(1 / 2 t)\left(d x / d Y_{i}\right) \\
& \times\left[\left(1-Y_{i}\right) \int_{-\infty}^{x} Y_{i} d x+Y_{i} \int_{x}^{\infty}\left(1-Y_{i}\right) d x\right], \\
\tilde{D}_{j j}^{k} & +\left(d C_{i} / d C_{j}\right) \tilde{D}_{j i}^{k}=(1 / 2 t)\left(d x / d Y_{j}\right) \\
& \times\left[\left(1-Y_{j}\right) \int_{-\infty}^{x} Y_{j} d x+Y_{j} \int_{x}^{\infty}\left(1-Y_{j}\right) d x\right], \\
Y_{i} & =\left(C_{i}-C_{i}^{-}\right) /\left(C_{i}^{+}-C_{i}^{-}\right),
\end{aligned}
$$

where both $\tilde{D}_{i i}^{k}$ and $\tilde{D}_{j j}^{k}$ are the major interdiffusion coefficients which represent the influence of concentration gradients of $i$ and $j$ elements upon their own fluxes, and $\tilde{D}_{i j}^{k}$ and $\tilde{D}_{j i}^{k}(i \neq j)$ are the cross diffusion coefficients which represent the influence of the concentration gradients of $i$ and $j$ elements on the fluxes of $j$ and $i$ elements, respectively. Here, the superscript symbol $k$ represents the host element, i.e. $\mathrm{Ni}$ in this case. These diffusion coefficients represent the diffusivity of the solute elements, $i$ and $j$, in the host element k. $C_{i}$ is the mole fraction of $i$ element, and $C_{i}^{+}$and $C_{i}^{-}$are the values of the mole fraction at the positions, $x=+\infty$ and $x=-\infty$ (corresponding to the two terminal alloys), respectively. The duration for interdiffusion is denoted by the symbol $t$.

From eqs. (1), (2) and (3) adopting the experimental data obtained from the two different diffusion couples composed in the same alloying system, we can calculate the interdiffusion coefficients at the chemical composition of the cross point of the two different diffusion paths which are obtained 
Table 1 Design of diffusion couple and the duration of diffusion annealing.

\begin{tabular}{cc}
\hline Diffusion couple & Duration, $t / \mathrm{h}$ \\
\hline Ni-Al-W system & 48 \\
Ni-5Al/Ni-5W & 110 \\
Ni/Ni-5Al-5W & \\
Ni-Al-Re system & \\
Ni-5Al/Ni-5Re & 192 \\
Ni/Ni-5Al-5Re & 192 \\
Ni-Al-Ru system & \\
Ni-8Al/Ni-8Ru & \\
Ni/Ni-8Al-8Ru & 48 \\
& 48 \\
$\mathrm{Ni}-\mathrm{Ru}-\mathrm{W}$ system & \\
$\mathrm{Ni}-8 \mathrm{Ru} / \mathrm{Ni}-5 \mathrm{~W}$ & \\
$\mathrm{Ni} / \mathrm{Ni}-8 \mathrm{Ru}-5 \mathrm{~W}$ & 48 \\
$\mathrm{Ni}-\mathrm{Ru}-\mathrm{Re}$ system & 48 \\
$\mathrm{Ni}-8 \mathrm{Ru} / \mathrm{Ni}-5 \mathrm{Re}$ & \\
$\mathrm{Ni} / \mathrm{Ni}-8 \mathrm{Ru}-5 \mathrm{Re}$ & \\
\hline
\end{tabular}

by tracing the concentration profiles measured from the two diffusion couples on the isothermal phase diagram of the employed ternary system.

\section{Experimental Procedure}

Pure Ni, Ni-5Al, Ni-8Al, Ni-5W, Ni-5Re, Ni-8Ru, Ni$5 \mathrm{Al}-5 \mathrm{~W}, \mathrm{Ni}-5 \mathrm{Al}-5 \mathrm{Re}, \mathrm{Ni}-8 \mathrm{Al}-8 \mathrm{Ru}, \mathrm{Ni}-8 \mathrm{Ru}-5 \mathrm{~W}$, and $\mathrm{Ni}-$ $8 \mathrm{Ru}-5 \mathrm{Re}(\mathrm{mol} \%)$ were arc-melted using $4 \mathrm{~N} \mathrm{Ni}, 4 \mathrm{~N} \mathrm{Al}, 2 \mathrm{~N}$ $\mathrm{W}, 2 \mathrm{~N} \mathrm{Re}$ and $3 \mathrm{~N} \mathrm{Ru}$ into the button shape ingots in high purity argon atmosphere. The compositions of the ternary alloys are selected so that the alloys are in the solid solution state at $1250^{\circ} \mathrm{C}$. The compositional homogenization and grain growth in each specimen cutting from the ingots were accomplished by cold rolling followed by annealing at $1250^{\circ} \mathrm{C}$.

Diffusion couples were prepared in the following way. Surface of the plate sample was mechanically ground using the emery papers followed by polishing using $0.25 \mu \mathrm{m}$ diamond slurry, and then the sample was washed in acetone with an ultrasonic cleaner. The diffusion couples were assembled as shown in Table 1. These couples were held tightly with molybdenum holders. At that time, alumina fibers were sandwiched between the samples of the couple as a marker indicating the initial interface.

Each diffusion couple was encapsulated in a quartz tube with argon and annealed at $1250^{\circ} \mathrm{C}$. The duration employed in each diffusion couples are also listed in Table 1. After this annealing, the section of each diffusion couple was examined with a scanning electron microscope (SEM) equipped with an energy dispersive X-ray spectrometer (EDX) so as to measure concentration profiles across the diffusion interface. The origin of the concentration profile is set at the position of the alumina fiber. (a)

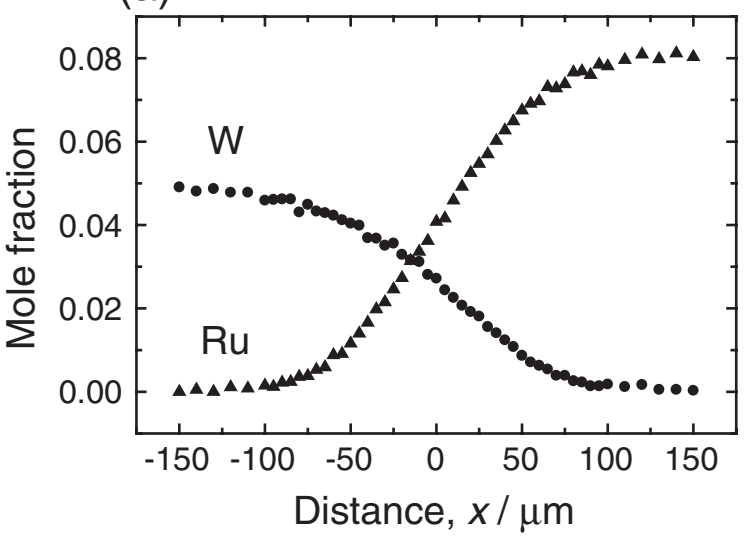

(b)

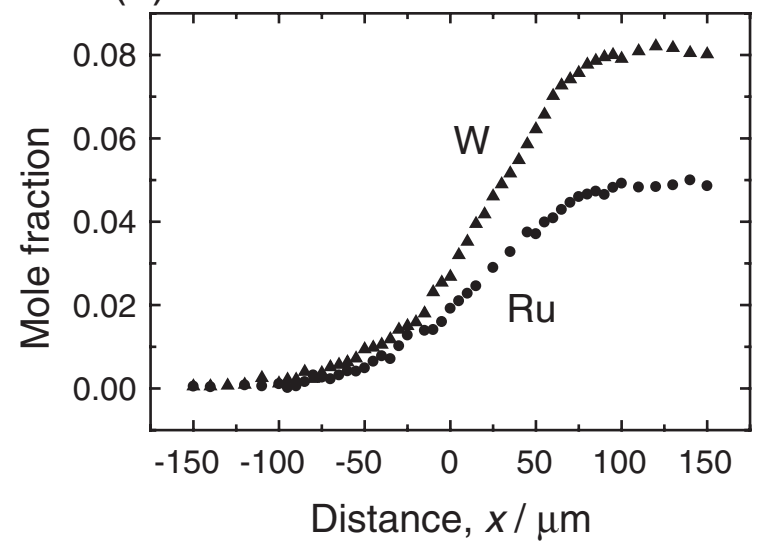

Fig. 1 Concentration profiles of $\mathrm{Ru}$ and $\mathrm{Re}$ obtained from (a) $\mathrm{Ni}-8 \mathrm{Ru} / \mathrm{Ni}-$ $5 \mathrm{~W}$ diffusion couple annealed at $1250^{\circ} \mathrm{C}$ for $48 \mathrm{~h}$ and (b) Ni/Ni-8Ru-5W diffusion couple annealed at $1250^{\circ} \mathrm{C}$ for $48 \mathrm{~h}$.

\section{Results and Discussion}

\subsection{Concentration profiles and diffusion path}

As the representative examples, the solute concentration profiles obtained from the diffusion couples are shown in Fig. 1 for $\mathrm{Ni}-\mathrm{Ru}-\mathrm{W}$ system and in Fig. 2 for $\mathrm{N}-\mathrm{Ru}-\mathrm{Re}$ system. The profiles exhibit sigmoidal curves without any discontinuity, indicating that the atomic diffusion occurred in the solid solution region of each alloying system. The diffusion paths can be obtained by replotting the data of Figs. 1 and 2 into the Gibbs triangle. The results are shown in Figs. 3 and 4, respectively. The chemical composition obtained from the cross point of the two diffusion paths was $\mathrm{Ni}-4.0 \mathrm{Ru}-2.6 \mathrm{~W}(\mathrm{~mol} \%)$ in $\mathrm{Ni}-\mathrm{Ru}-\mathrm{W}$ system and $\mathrm{Ni}-$ $3.8 \mathrm{Ru}-2.6 \mathrm{Re}(\mathrm{mol} \%)$ in $\mathrm{Ni}-\mathrm{Ru}-\mathrm{Re}$ system. In a similar way, chemical composition at the cross point was obtained in each alloying system employed in this study. The results are summarized in Table 2. The composition at the cross point was used for calculating interdiffusion coefficients by the modified Boltzmann-Matano method as will be shown in the next section.

\subsection{Interdiffusion coefficients}

On the basis of the modified ternary Boltzmann-Matano method represented by eqs. (1), (2) and (3), the interdiffusion 
(a)

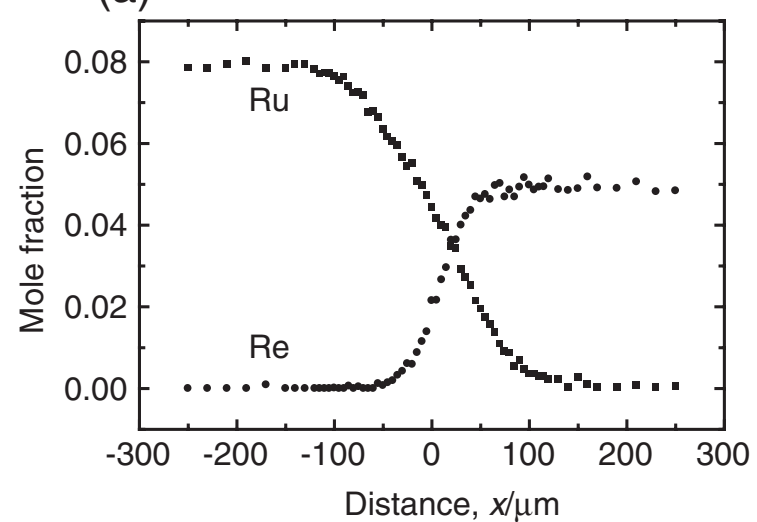

(b)

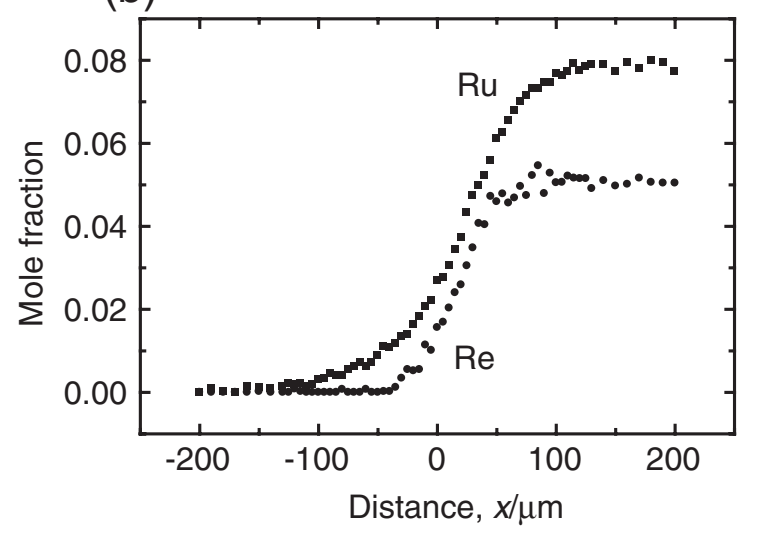

Fig. 2 Concentration profiles of $\mathrm{Ru}$ and $\mathrm{Re}$ obtained from (a) $\mathrm{Ni}-8 \mathrm{Ru} / \mathrm{Ni}-$ $5 \mathrm{Re}$ diffusion couple annealed at $1250^{\circ} \mathrm{C}$ for $72 \mathrm{~h}$ and (b) Ni/Ni-8Ru-5Re diffusion couple annealed at $1250^{\circ} \mathrm{C}$ for $72 \mathrm{~h}$.

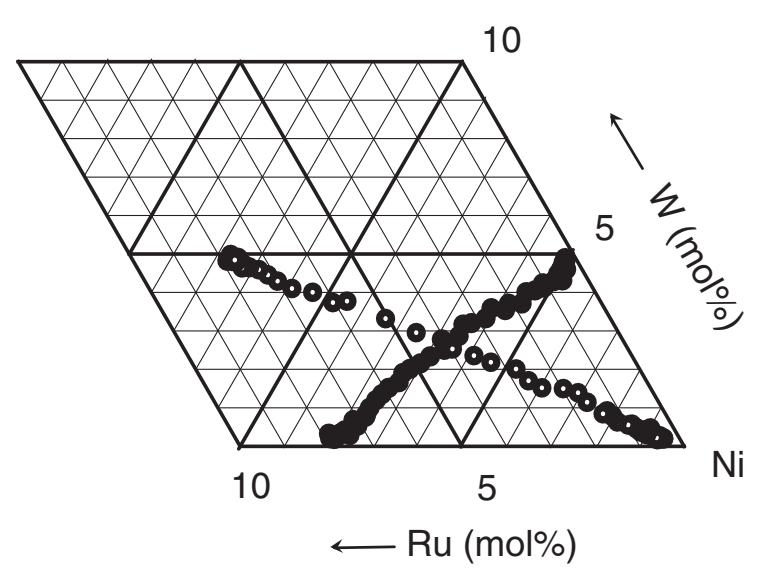

Fig. 3 Diffusion paths obtained from concentration profiles of diffusion couples in $\mathrm{Ni}-\mathrm{Ru}-\mathrm{W}$ system.

coefficients were obtained in the following way. Firstly, $Y_{i}$ values are calculated using eq. (3) from the experimental data on the concentration profiles and then they are plotted against $x$. Also, the relationship between $C_{i}$ and $C_{j}$ was obtained from the experimental data. Secondly, in order to obtain suitable functions representing the $Y_{i}-x$ profile and the $C_{i}-C_{j}$ profile, the least square fitting was carried out. Thirdly, both the derivative terms and the integration terms in eqs. (1) and (2) were calculated using the functions deter-

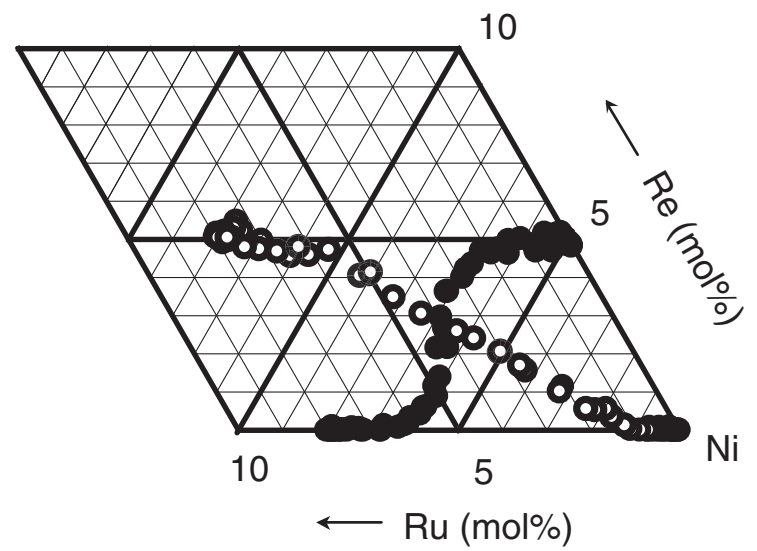

Fig. 4 Diffusion paths obtained from concentration profiles of diffusion couples in $\mathrm{Ni}-\mathrm{Ru}-\mathrm{Re}$ system.

Table 2 Chemical composition of the cross point of diffusion paths and interdiffusion coefficients in each alloying system.

\begin{tabular}{|c|c|c|c|}
\hline System & $\begin{array}{l}\text { Cross point } \\
(\mathrm{mol} \%)\end{array}$ & $\begin{array}{c}\text { Variety of } \\
\text { coefficients }\end{array}$ & $\begin{array}{c}\text { Interdiffusion } \\
\text { coefficient, } \tilde{D}_{i j}^{\mathrm{Ni}} / \mathrm{m}^{2} \mathrm{~s}^{-1}\end{array}$ \\
\hline \multirow[t]{4}{*}{$\mathrm{Ni}-\mathrm{Al}-\mathrm{W}$} & $\mathrm{Ni}-2.7 \mathrm{Al}-3.3 \mathrm{~W}$ & $\tilde{D}_{\mathrm{WW}}^{\mathrm{Ni}}$ & $9.3 \times 10^{-15}$ \\
\hline & & $\tilde{D}_{\mathrm{WAl}}^{\mathrm{Ni}}$ & $-2.6 \times 10^{-15}$ \\
\hline & & $\tilde{D}_{\mathrm{AlW}}^{\mathrm{Ni}}$ & $6.2 \times 10^{-15}$ \\
\hline & & $\tilde{D}_{\mathrm{AlAl}}^{\mathrm{Ni}}$ & $8.6 \times 10^{-14}$ \\
\hline \multirow[t]{4}{*}{$\mathrm{Ni}-\mathrm{Al}-\mathrm{Re}$} & $\mathrm{Ni}-2.9 \mathrm{Al}-4.2 \mathrm{Re}$ & $\tilde{D}_{\operatorname{Re} R e}^{\mathrm{Ni}}$ & $2.0 \times 10^{-15}$ \\
\hline & & $\tilde{D}_{\mathrm{ReAl}}^{\mathrm{Ni}}$ & $-1.2 \times 10^{-15}$ \\
\hline & & $\tilde{D}_{\mathrm{AlRe}}^{\mathrm{Ni}}$ & $7.7 \times 10^{-15}$ \\
\hline & & $\tilde{D}_{\mathrm{AlAl}}^{\mathrm{Ni}}$ & $6.2 \times 10^{-14}$ \\
\hline \multirow[t]{4}{*}{$\mathrm{Ni}-\mathrm{Al}-\mathrm{Ru}$} & $\mathrm{Ni}-5.0 \mathrm{Al}-5.3 \mathrm{Ru}$ & $\tilde{D}_{\mathrm{RuRu}}^{\mathrm{Ni}}$ & $8.5 \times 10^{-15}$ \\
\hline & & $\tilde{D}_{\mathrm{RuAl}}^{\mathrm{Ni}}$ & $-2.3 \times 10^{-15}$ \\
\hline & & $\tilde{D}_{\mathrm{AlRu}}^{\mathrm{Ni}}$ & $5.6 \times 10^{-15}$ \\
\hline & & $\tilde{D}_{\mathrm{AlAl}}^{\mathrm{Ni}}$ & $1.2 \times 10^{-13}$ \\
\hline \multirow[t]{4}{*}{$\mathrm{Ni}-\mathrm{Ru}-\mathrm{W}$} & $\mathrm{Ni}-4.0 \mathrm{Ru}-2.6 \mathrm{~W}$ & $\tilde{D}_{\mathrm{WW}}^{\mathrm{Ni}}$ & $6.9 \times 10^{-15}$ \\
\hline & & $\tilde{D}_{\mathrm{WRu}}^{\mathrm{Ni}}$ & $-5.2 \times 10^{-16}$ \\
\hline & & $\tilde{D}_{\mathrm{RuW}}^{\mathrm{Ni}}$ & $-1.4 \times 10^{-15}$ \\
\hline & & $\tilde{D}_{\mathrm{RuRu}}^{\mathrm{Ni}}$ & $6.3 \times 10^{-15}$ \\
\hline \multirow[t]{4}{*}{$\mathrm{Ni}-\mathrm{Ru}-\mathrm{Re}$} & $\mathrm{Ni}-3.8 \mathrm{Ru}-2.6 \mathrm{Re}$ & $\tilde{D}_{\operatorname{Re} \mathrm{Re}}^{\mathrm{Ni}}$ & $1.3 \times 10^{-15}$ \\
\hline & & $\tilde{D}_{\mathrm{ReRu}}^{\mathrm{Ni}}$ & $9.0 \times 10^{-17}$ \\
\hline & & $\tilde{D}_{\mathrm{RuRe}}^{\mathrm{Ni}}$ & $-1.0 \times 10^{-15}$ \\
\hline & & $\tilde{D}_{\mathrm{RuRu}}^{\mathrm{Ni}}$ & $5.3 \times 10^{-15}$ \\
\hline
\end{tabular}

mined by the least square fitting. Here, the $x$ value as the integration range of eqs. (1) and (2) was determined from the composition at the cross point of the two diffusion paths. The procedure using the data obtained from the two different diffusion couples gave a set of simultaneous equations. Then the interdiffusion coefficients were obtained by solving the simultaneous equations. The calculated results are shown in Table 2. The values in the table are the interdiffusion coefficients at the compositions of the cross points of the diffusion paths in the solid solution phase. 
Table 3 Effective interdiffusion coefficients.

\begin{tabular}{ccc}
\hline Diffusion couple & Element, $i$ & $\begin{array}{c}\text { Effective interdiffusion } \\
\text { coefficient, } \tilde{D}_{i}^{\text {eff }} / \mathrm{m}^{2} \mathrm{~s}^{-1}\end{array}$ \\
\hline $\mathrm{Ni}-5 \mathrm{Al} / \mathrm{Ni}-5 \mathrm{~W}$ & $\mathrm{~W}$ & $1.0 \times 10^{-14}$ \\
$\mathrm{Ni} / \mathrm{Ni}-5 \mathrm{Al}-5 \mathrm{~W}$ & $\mathrm{~W}$ & $7.1 \times 10^{-14}$ \\
& $\mathrm{Al}$ & $8.4 \times 10^{-15}$ \\
$\mathrm{Ni}-5 \mathrm{Al} / \mathrm{Ni}-5 \mathrm{Re}$ & $\mathrm{Re}$ & $1.0 \times 10^{-13}$ \\
& $\mathrm{Al}$ & $2.4 \times 10^{-15}$ \\
$\mathrm{Ni} / \mathrm{Ni}-5 \mathrm{Al}-5 \mathrm{Re}$ & $\mathrm{Re}$ & $4.0 \times 10^{-14}$ \\
& $\mathrm{Al}$ & $1.8 \times 10^{-15}$ \\
$\mathrm{Ni}-8 \mathrm{Al} / \mathrm{Ni}-8 \mathrm{Ru}$ & $\mathrm{Ru}$ & $1.0 \times 10^{-13}$ \\
& $\mathrm{Al}$ & $9.3 \times 10^{-15}$ \\
$\mathrm{Ni} / \mathrm{Ni}-8 \mathrm{Al}-8 \mathrm{Ru}$ & $\mathrm{Ru}$ & $1.0 \times 10^{-13}$ \\
& $\mathrm{Al}$ & $7.9 \times 10^{-15}$ \\
$\mathrm{Ni}-8 \mathrm{Ru} / \mathrm{Ni}-5 \mathrm{~W}$ & $\mathrm{~W}$ & $1.4 \times 10^{-13}$ \\
& $\mathrm{Ru}$ & $7.8 \times 10^{-15}$ \\
$\mathrm{Ni} / \mathrm{Ni}-8 \mathrm{Ru}-5 \mathrm{~W}$ & $\mathrm{~W}$ & $7.1 \times 10^{-15}$ \\
& $\mathrm{Ru}$ & $6.0 \times 10^{-15}$ \\
$\mathrm{Ni}-8 \mathrm{Ru} / \mathrm{Ni}-5 \mathrm{Re}$ & $\mathrm{Re}$ & $5.5 \times 10^{-15}$ \\
$\mathrm{Ni} / \mathrm{Ni}-8 \mathrm{Ru}-5 \mathrm{Re}$ & $\mathrm{Ru}$ & $1.2 \times 10^{-15}$ \\
& & $6.9 \times 10^{-15}$ \\
& & $1.4 \times 10^{-15}$ \\
& & $4.1 \times 10^{-15}$ \\
\hline
\end{tabular}

Table 4 Interdiffusion coefficient in binary system. ${ }^{8,9)}$

\begin{tabular}{cc}
\hline $\begin{array}{c}\text { Composition } \\
(\mathrm{mol} \%)\end{array}$ & $\begin{array}{c}\text { Interdiffusion } \\
\text { coefficient, } \tilde{D} / \mathrm{m}^{2} \mathrm{~s}^{-1}\end{array}$ \\
\hline $\mathrm{Ni}-x \mathrm{~W}(0<x<3.4)$ & $7.1 \times 10^{-15}$ \\
$\mathrm{Ni}-x \mathrm{Re}(0<x<3.4)$ & $1.5 \times 10^{-15}$ \\
$\mathrm{Ni}-x \mathrm{Ru}(0<x<6.06)$ & $9.0 \times 10^{-15}$ \\
\hline
\end{tabular}

\subsection{Effective interdiffusion coefficients}

Dayananda and Behnke introduced the effective interdiffusion coefficient $\tilde{D}_{i}^{\text {eff }},{ }^{9)}$ and this is defined in a ternary system as the following equation,

$$
\tilde{D}_{i}^{\mathrm{eff}} \equiv \tilde{D}_{i i}^{k}+\tilde{D}_{i j}^{k} \frac{\partial C_{j} / \partial x}{\partial C_{i} / \partial x}
$$

This means the sum of the main interdiffusion coefficient and the cross interdiffusion coefficient weighted by the proportion of concentration gradients, i.e., the effective interdiffusion coefficient involves the effect of cross interdiffusion coefficient. The effective interdiffusion coefficients in each diffusion couple of this study are summarized in Table 3. Also, interdiffusion coefficients reported previously in Ni-W, $\mathrm{Ni}-\mathrm{Re}$ and Ni-Ru binary systems are shown in Table $4 .{ }^{10,11)}$ Comparing the results on the refractory elements in Table 3 to those in Table 4, it can be said that the effective interdiffusion coefficients of both $\mathrm{W}$ and Re are similar to those of the binary interdiffusion coefficients. This fact suggests that the cross interdiffusion coefficients of the two refractory elements are smaller than the main interdiffusion coefficients. In other words, the effect of $\mathrm{Al}$ or $\mathrm{Ru}$ on the diffusivity of both $\mathrm{W}$ and $\mathrm{Re}$ in $\mathrm{Ni}$ is small. In particular, the effect of Ru on the diffusivity of Re in $\mathrm{Ni}, \tilde{D}_{\mathrm{ReRu}}^{\mathrm{Ni}}$, is much smaller by an order of magnitude than the main interdiffusion coefficient of Re in Ni, $\tilde{D}_{\mathrm{ReRe}}^{\mathrm{Ni}}$, as shown in Table 2.
According to the work done by Kirkaldy et al. the relationship between the major interdiffusion coefficient and the cross interdiffusion coefficient can be expressed by the following equation if the alloy is assumed as a dilute solution. ${ }^{5)}$

$$
\tilde{D}_{i j}^{k} / \tilde{D}_{i i}^{k}=\left(1+\varepsilon_{i j}\right) C_{i}
$$

where $\varepsilon_{i j}$ is the Wagner's interaction parameter between $i$ and $j$ elements. The fact that $\tilde{D}_{\mathrm{ReRu}}^{\mathrm{Ni}}$ is much smaller than $\tilde{D}_{\mathrm{ReRe}}^{\mathrm{Ni}}$ implies that the thermodynamic interaction between $\mathrm{Ru}$ and $\mathrm{Re}$ is negligible. Therefore, it can be concluded that Ru scarcely changes the distribution behaviour of Re into the $\gamma$ and the $\gamma^{\prime}$ phases, although the influence of $\mathrm{Ru}$ on the distribution of the refractory elements in nickel-based superalloys was a matter of debate.

\section{Conclusion}

The interdiffusion coefficients in the solid solution phase of $\mathrm{Ni}-\mathrm{X}-\mathrm{Y}(\mathrm{X}, \mathrm{Y}$ : Re, $\mathrm{W}, \mathrm{Ru}, \mathrm{Al})$ ternary systems as the fundamental systems of Ni-based superalloys were evaluated by a series of experiments.

The interdiffusion coefficients obtained in this study are summarized in Table 2. In these ternary systems, the cross interdiffusion coefficients of refractory elements (W, Re) were smaller than the main interdiffusion coefficients. In particular, $\tilde{D}_{\mathrm{ReRu}}^{\mathrm{Ni}}$ was much smaller than $\tilde{D}_{\mathrm{ReRe}}^{\mathrm{Ni}}$.

\section{Acknowledgements}

This work was supported in part by the Grant-in-Aid for Scientific Research of Japan Society for the Promotion of Science (JSPS), Japan. Also, a part of this work was supported by "Nanotechnology Support Project of the Ministry of Education, Culture, Sports, Science and Technology (MEXT), Japan" in the Research Center for Ultrahigh Voltage Electron Microscopy, Osaka University.

\section{REFERENCES}

1) K. Matsugi, S. Miyazaki, Y. Murata, M. Morinaga and N. Yukawa: Tetsu-To-Hagane 78 (1992) 658-665.

2) K. Matsugi, Y. Murata, M. Morinaga and N. Yukawa: Proc. of the 7th Int. Symp. on Superalloys 1992, Ed. by S. D. Antolovich et al. pp. 307316.

3) T. Hino, Y. Yoshioka, Y. Ishiwata, K. Nagata, T. Kobayashi, Y. Koizumi, H. Harada and T. Yamagata: Report of the 123rd Committee on Heat-Resisting Materials and Alloys (Japan Society for the Promotion of Science) 40 (1999) 141-150.

4) T. Yokokawa, M. Osawa, K. Nishida, Y. Koizumi, T. Kobayashi and H. Harada: J. Jpn. Inst. Met. 68 (2004) 138-141.

5) J. S. Kirkaldy, Z. U. Haq and L. C. Brown: Trans. ASM 56 (1963) 834849.

6) M. Hattori, N. Goto, Y. Murata, T. Koyama and M. Morinaga: Mater. Trans. 46 (2005) 163-166.

7) M. S. A. Karunaratne, P. Carter and R. C. Reed: Acta Mater. 49 (2001) 861-875.

8) D. P. Whittle and A. Green: Scr. Metall. 8 (1974) 883-884.

9) M. A. Dayananda and D. A. Behnke: Scr. Metall. 25 (1991) 21872191.

10) M. S. A. Karunaratne, P. Carter and R. C. Reed: Mater. Sci. Eng. A 281 (2000) 229-233.

11) M. S. A. Karunaratne and R. C. Reed: Acta Mater. 51 (2003) 29052919. 